\title{
Neighborhood Social Capital, Neighborhood Disadvantage, and Change of Neighborhood as Predictors of School Readiness
}

\author{
Charles Jones ${ }^{1}$ and Jing Shen ${ }^{2}$ \\ ${ }^{1}$ Department of Sociology, University of Toronto, 725 Spadina Avenue, Toronto, ON, Canada M5S 2J4 \\ ${ }^{2}$ The Prentice Institute for Global Population \& Economy, University of Lethbridge, 4401 University Drive West, \\ Lethbridge, AB, Canada T1K $3 M 4$ \\ Correspondence should be addressed to Charles Jones; cjonescan@gmail.com
}

Received 19 August 2013; Accepted 7 January 2014; Published 26 February 2014

Academic Editor: Joris Hoekstra

Copyright (C) 2014 C. Jones and J. Shen. This is an open access article distributed under the Creative Commons Attribution License, which permits unrestricted use, distribution, and reproduction in any medium, provided the original work is properly cited.

\begin{abstract}
Neighborhood income and social capital are considered important for child development, but social capital has rarely been measured directly at an aggregate level. We used Canadian data to derive measures of social capital from aggregated parental judgments of neighborhood collective efficacy and neighborhood safety. Measures of neighborhood income came from Census data. Direct measures of preschoolers' school readiness were predicted from neighborhood-level variables, with regional indicators and household/parental characteristics taken into account. Our findings show that (1) residing in Quebec, being Black, and having a parent who was born outside Canada are positively associated with children's living in disadvantaged or low collective efficacy neighborhoods as well as with their living in low-income households. (2) Children's odds of residential mobility were reduced when the origin neighborhood had higher collective efficacy but increased when the family rented rather than owned. (3) Both neighborhood collective efficacy and children's ever having lived in a poor neighborhood were correlated with receptive vocabulary scores, but results were mixed for other cognitive dimensions. Children of younger mothers scored worse on receptive vocabulary. There were similar patterns for demographic predictors related to visible minority status, sibship size, and birth order. Neighborhood average income had no effect on cognitive outcomes when the region was controlled.
\end{abstract}

\section{Introduction}

It has been amply documented that working class and minority children do worse in school than otherwise comparable middle class children from dominant ethnic groups. Working class and minority children's poorer school performance, in turn, leads them to worse jobs and lower income than they might otherwise have achieved. In recent years a sophisticated literature has grown to show how processes involving household-level characteristics, such as poverty, operate within the contexts defined by neighborhoods and communities. The existing studies have suggested the importance of distinguishing neighborhood-level effects on child outcomes from those at the household level. Although some families indeed move to economically more advantaged neighborhoods, as their household finances permit, persistent racial, ethnic, and linguistic segregation makes it much less likely for disadvantaged families to move.

This study therefore offers a fresh perspective on the "neighborhood effects" literature. Focusing on a nationally representative, longitudinal sample of young children in Canada, we investigate how neighborhood characteristics affect cognitive dimensions of school readiness, independent from household characteristics, in the dimensions of both economic capital and social capital. We find that economic and social capital characteristics of neighborhoods have significant impacts on children's vocabulary-related test performance in Canada's official languages (English or French) but have no influence on their performance in tests that are not vocabulary based, such as copying, symbol manipulation, and mathematics. 


\section{Literature Review}

A well-established body of scholarship shows that household poverty has long-term detrimental effects on children and adolescents [1]. Lower levels of household income may also lead teenagers to take on paid work at a level that interferes with school achievement during their high school years. If the percentage of households that are below the poverty-line is greater than a critical prevalence within a neighborhood or community, this neighborhood or community is usually defined as a disadvantaged one. Although the threshold to define poverty is often arbitrary, by relying on the Canadian Census data, researchers have agreed that a Census Tract is to be considered disadvantaged, if the percentage of families below the Low Income Cutoff (LICO, defined by the Statistics Canada) in this Census Tract is more than twice the national average percentage. This kind of neighborhoods tends to include higher proportions of single parent families and is often considered socially disorganized and lacking social cohesion [2]. Those contextual characteristics contribute to lesser involvement of parents in their children's schooling, which is, in turn, associated with children's lower levels of academic achievements and higher risks of school dropout.

Over the last decade, scholars have given more attention to neighborhood characteristics that go beyond the economic dimension. By focusing on urban planning, particularly real estate and construction industries, scholars have noticed how the creation of mixed income communities might generate social benefits or "social capital" [3]. Neighborhood-level "social capital" has been defined as "the networks, norms, values and understandings that facilitate cooperation within or among groups" $[4,5]$. Neighborhood social capital as a measurable concept is hard to distinguish from "collective efficacy" or "social cohesiveness" [6-10]. While neighborhood advantage is strongly linked to income levels, neighborhood social capital has been associated with at least some of the following characteristics: civic participation [11, 12], a high rate of home ownership, membership in religious and other voluntary organizations, and pride in local schools or in a common ethnic or language heritage. Neighborhoods with high levels of social capital provide mutual support and surveillance and are likely to be more effective in "not in my backyard" (NIMBY) type of collective actions, such as resisting the placement of undesired facilities (halfway houses, generating stations, high rise buildings, etc.). Thus, neighborhood social capital should be conceptually distinct from neighborhood economic capital, even though the two are likely to be positively correlated.

Scholars have long been concerned about a practical question, namely, whether or not neighborhood characteristics have influences on residing individuals beyond the aggregated impacts of household income, housing tenure, and employment status. Some studies challenge the claim that neighborhoods can be more than the sum of their parts [13], while others argue that instead of investing in more expensive programs, such as making changes in social assistance or other transfer payments to households, mixed housing and other community-based policies would be an effective alternative to increase social capital.
Because it is difficult, if not impossible, to demonstrate causal relationships between the neighborhood characteristics and outcomes at the individual level, large scale randomassignment field experiments attract well-deserved attention. Such studies are carried out with members of dependent populations, most often those in social (public) housing. The Moving To Opportunity (MTO) studies, carried out in Baltimore, Boston, Chicago, Los Angeles, and New York in the mid-1990s are the best known, though there has been much debate about the degree to which intended objectives were achieved [14-17]. The MTO studies used a lottery to allocate housing vouchers to families living in public housing in high-poverty neighborhoods. The experimental group received a housing voucher with the restriction that they take up residence in a Census tract with a poverty rate of less than 10 percent. Control groups were those who remained in public housing and another group that received a housing voucher, without geographic restriction. Results from the MTO studies varied widely, and both the "neighborhood social capital" supporters and opponents could base their arguments on some part of empirical evidence.

More recent research is a well-exemplified review by Sampson et al. [18] and in volumes edited by van Ham and colleagues $[19,20]$. Despite contributions made by the existing literature, an important theme is somewhat overlooked by scholars. Namely, while residential choices are limited by direct discrimination (particularly in the United States), most households locate in one neighborhood or another according to their members' aspirations, their preferences for living near friends and families, their household income, and stages in the life cycle. For this reason, the seemingly apparent effects of neighborhoods reflect, in large part, earlier decisions made at the household level, as families sort themselves into one residential neighborhood or another [21].

While the replication of experiments such as MTO is highly desirable, it would also be useful for observational studies to make separate measurements of neighborhood economic deprivation and neighborhood social capital. Thus, in this study, we aim to show how one measure of neighborhood social capital is associated with different aspects of children's school readiness, independently from the impacts of neighborhood economic characteristics.

\section{Hypotheses}

The spatial concentration of household poverty has increased over recent decades in the United States [22-24]. Ecological research carried out in a number of cities has further indicated that social problems such as crime, school dropout, public disorder, and child maltreatment are correlated with geographically concentrated low income and family instability [25]. A similar trend of increasing spatial concentration of low income has been reported in Canada with similar implications for child welfare [26-33]. It is important to measure children's repeated exposure to low household income insofar as such lack of resources may trap children and their families in undesirable neighborhoods. This question has been infrequently addressed in the Canadian literature to date, 
since most empirical studies have been cross-sectional and thus unable to separate those children whose experience of low household income or neighborhood disadvantage is long-term from those whose experience is transitory.

Spatial concentration of economic and social disadvantage is statistically linked to concentration of ethnic, linguistic, racial, religious, or visible minority groups. In earlier decades of the last century, low-income neighborhoods in immigrant-receiving cities of North America were dominated by European immigrants, many of whom retained their original cultures, languages, and religious practices for at least one or two generations before they and their offspring or grandchildren became fully assimilated. The US literature has focused on the increasing concentration of minority residents, largely African-Americans, in the most impoverished areas of the nation's metropolises from the 1960s [34]. By contrast, Canadian cities have traditionally included immigrant neighborhoods occupied in various decades by Chinese, Haitians, Hungarians, Italians, Jamaicans, Japanese, Jews, Irish, Koreans, Latin Americans, Pakistanis, Poles, Portuguese, Somalis, Tamils, Ukrainians, Vietnamese among others [35]. Some Canadian cities include neighborhoods with significant concentrations of American Indians, though Indian Reservations usually form rural communities. There have also been English-speaking communities (often advantaged ones) in Quebec (dominated by French-speaking residents) and French-speaking communities in Western Canada (dominated by English-speaking residents). In short, indicators of neighborhood or community disadvantage usually parallel other characteristics such as racial composition, immigrant status, or language use, in the neighborhood or community.

The neighborhood social capital perspective [36, 37] claims that social capital can counteract the negative effects of household and neighborhood poverty. For example, although economic disadvantage is associated with a low socioeconomic status, some "ethnic enclaves" could have strong internal social networks, collective efficacy, and social cohesion due to the sharing of a common heritage [38-40]. According to some scholars [41-43], collective efficacy is indicated by the level of trust and attachment among neighbors, the extent of informal social control, and the degree to which collective goals can be achieved. One of the motivating assumptions behind the MTO experiments was the idea: Children from low-income urban neighborhoods with a relatively high level of collective efficacy would tend to have better school performances than children from economically comparable neighborhoods that have a low level of collective efficacy. Namely, social capital effect is independent of that of economic capital at the neighborhood level. Disadvantaged households may have a relatively high risk of residing in socioeconomically disadvantaged neighborhoods. However, the disadvantages at the household level does not necessarily leads to children's exposure to a low level of social capital at the neighborhood level. We thus hypothesize that.

Hypothesis 1. Other characteristics being equal, children who were born in visible minority households, whose parents are immigrants, and whose parents do not speak English or
French, are more likely to be trapped in long-term household poverty. However, this may not necessarily lead to children's exposure to neighborhoods that lack social capital.

Moreover, concerning the length of children's exposure to disorganized communities, we hypothesize that.

Hypothesis 2. The higher the level of collective efficacy of a neighborhood, the lower the odds of changing neighborhoods.

A neighborhood's economic status is highly correlated with the quality of local schools, which should affect children's educational attainment once they are in the school system. Cognitive development prior to starting school is influenced by both household and neighborhood factors. We propose that neighborhood effects on preschoolers are mainly seen in the development of children's communication-related abilities. This is because the safer and more friendly the neighborhood is, the more likely it is that neighborhood residents would allow their children to interact with other residents, through visiting other households or playing with peers at the community playground. All those social activities benefit the development of children's social and communication abilities directly. Therefore, we hypothesize that social capital characteristics of a neighborhood directly influence children's socially related or communication abilities but have no direct effect on their other abilities measured, for example, mathematical and symbol manipulation tasks.

The higher the collective efficacy level of a neighborhood, the better the children's social and communication abilities.

Hypothesis 3. Children's social and communication abilities are relatively poorer if they have ever lived in a poor neighborhood.

\section{Data, Measurement, and Methods}

Data used in this study came from two major sources. The National Longitudinal Survey of Children and Youth (NLSCY hereafter) is the primary data source. This is a multiyear project that collects data representing selected cross-sectional and longitudinal populations of children and youth in Canada's ten provinces. It is comparable to the Millennium Cohort Survey in the United Kingdom and the Early Childhood Longitudinal Survey (ECLS) in the United States. Data collection has taken place every two years, starting with a sample of 22,000 children in 1994-95. Combining all cohorts to date, data have been gathered from around 150,000 children. However, this paper focuses only on the longitudinal population corresponding to a subset of the Cycle 3 Early Child Development (ECD hereafter) cohort. This is by far the largest NLSCY cohort and was first interviewed when the selected children were under two years old in 1998-99 and then reinterviewed and tested on two subsequent occasions. Cognitive tests were administered by interviewers and much of the remaining information was collected by questioning the "Person Most Knowledgeable" (PMK) about the child. We use the term parent below, since the PMK is almost always a parent. 
Our second major data source is neighborhood and community profiles collected in Canada Census. Six-character postal codes were used to match the Census records to the households of children from the NLSCY. Postal codes of this kind are used for administrative purposes by Canada Post, defining geographical units down to the level of a delivery person's walking distance. Thus, they are more geographically detailed than zip codes used by the United States Postal Service.

4.1. Neighborhood-Level Variables. First, we define which neighborhoods are economically disadvantaged. The Low Income Cutoff (LICO hereafter) from Statistics Canada is the widely accepted indicator of neighborhood poverty. According to Hatfield's [44] definition, a neighborhood with more than twice the national average percent of families below the LICO is considered in "high poverty." Using this approach, in a study conducted in Winnipeg, neighborhoods were classified as in "low poverty" ( $0-16 \%$ below LICO), "moderate poverty" (16.1-32\% below LICO), "high poverty" (32.1-50\% below LICO), and "very high poverty" (over 50\% below LICO [45]). In another study conducted about schools in Vancouver, a school was considered in a neighborhood with "high poverty," if the neighborhood had more than $32.6 \%$ of families below the LICO (twice the 1996 Census national average of $16.3 \%$ ) [46]. Similar approaches were used to identify low-income neighborhoods in Montreal, such as Villeray-Saint-Michel-Parc-Extension (34.3\% poor families), Montréal-Nord (33.2\%), and Montréal Sud-Ouest (32.8\%) $[47,48]$.

Besides measuring the economic status of a neighborhood, we made direct measurement of the level of social capital in a neighborhood. Unlike Sampson, Raudenbush, and Earls, who used small groups of trained observers to rate each neighborhood's level of social capital, we used the judgments of parents. The NLSCY includes questions derived from instruments developed by Barnes McGuire for use in Boston and Chicago [49]. We created "collective efficacy" scores (also called the "neighborhood's score") and "neighborhood safety" scores by aggregating all available parental judgments to local geographical areas. This means that we pooled judgments for all parent informants from data collection Cycles 1 to 7 of the NLSCY, resulting in the aggregation of judgments made by over 100,000 parents. Parental judgments were aggregated four times: to the sixcharacter post code, to the five-character post code, to the four-character post code, and to the forward sortation area (the first three characters). Using a look-up algorithm, we matched each child's record to a corresponding neighborhood. The algorithm first tried matching the child's full post code with the six-character postal code file that contained aggregated "collective efficacy" and "neighborhood safety" scores. If the match fails, the algorithm would remove the last character from the full post code and attempt to match the child's truncated postal code with the five-character post code file that contains the "collective efficacy" and "neighborhood safety" variables. If the match is not yet found, the algorithm would continue up to the three-character Forward Sorting
Area level (FSA), where over 95\% of child records had been matched to "collective efficacy" and "neighborhood safety" mean scores.

The aggregated "collective efficacy" score is based on the average of independent judgments made by adults who share the same postal codes (in six, five, four, and three characters, resp.). By treating it as an approach to imputation, we used the average scores of individual judgments on several items to estimate neighborhood collective efficacy and safety. For example, "Are people around here willing to help their neighbors?" "Is it safe to walk alone in this neighborhood after dark?" or "Can you reply on your neighbors to babysit your children when you are away?" Postal code neighborhoods whose average scores were at or below the level implied by the "neutral" response options of neighbor scale items are considered unneighborly or unsafe.

4.2. Direct Measures of Children's Abilities. Dependent variables consist of cognitive tests measuring abilities in three dimensions: receptive vocabulary, copying or symbol use, and number knowledge.

Receptive vocabulary was measured by the Peabody Component (Peabody Picture Vocabulary Test/Echelle de Vocabulaire en Images Peabody, Revised-PPVT-R) in English or French as preferred. The interviewer administered it to each selected child between 4 and 5 years old. We used age-standardized scores provided by Statistics Canada. The PPVT-R was designed to assess receptive vocabulary, while the remaining cognitive measures were less language based.

The copying or symbol-use test, also called "Who Am I?" test, generated an overall score as well as two subtest scores. The "Who am I?" questionnaire evaluates the developmental level of preschool children. The interviewer gave the child a booklet to complete with tasks such as copying shapes and writing numbers, letters, and sentences [50]. The overall "Who Am I?" assessment measures the child's understanding and use of conventional symbols as well as other relevant early learning skills. The Copying score assesses the development of the ability to conceptualize a given figure. The Symbols score assesses the child's understanding of symbols that have particular meanings.

"Number knowledge" is a direct measure that assesses the child's understanding of the concept of quantities and of the system of numbers. The interviewer asked the child the number knowledge component questions directly. Children had access to aids such as chips and a number card to help solve the problems but were not permitted to use pencil and paper. This test is based on the theory that four developmental levels can be distinguished in children's understanding of numbers: predimensional, unidimensional, bidimensional, and integrated bidimensional [51].

4.3. Statistical Methods. Given the complex design of the NLSCY, it is important to use balanced randomized replication estimates to obtain correct parameter estimates with valid standard errors. Bootstrap weights appropriate to the longitudinal population of interest were provided by Statistics Canada. These adjust for stratification and clustering in 
TABle 1: Predicting repeated exposures to household or neighbourhood disadvantage from age 1 to age 5.

\begin{tabular}{|c|c|c|c|c|}
\hline & \multicolumn{4}{|c|}{ Interval estimate (95\%) } \\
\hline & Estimate & Lower & Upper & $\mathrm{CV}^{*}$ \\
\hline Child household ever below LICO & $27.7 \%$ & $25.6 \%$ & $29.8 \%$ & 3.9 \\
\hline Child ever in a census tract with more than $32 \%$ below LICO & $8.1 \%$ & $6.8 \%$ & $9.4 \%$ & 8.4 \\
\hline Child in a household below LICO three times out of three & $7.1 \%$ & $5.8 \%$ & $8.4 \%$ & 9.2 \\
\hline Child in census tract with more than $32 \%$ below LICO on all three occasions & $4.3 \%$ & $3.3 \%$ & $5.3 \%$ & 12.0 \\
\hline Child ever in a neighbourhood judged unfavourably on neighbours score & $12.3 \%$ & $10.7 \%$ & $13.8 \%$ & 6.4 \\
\hline Child in a neighbourhood judged unfavourably on all three occasions & $4.2 \%$ & $3.3 \%$ & $5.1 \%$ & 11.0 \\
\hline Child changed residence between cycles 3 and 5 & $37.2 \%$ & $34.7 \%$ & $39.7 \%$ & 3.4 \\
\hline Child changed residence between cycles 4 and 5 & $19.4 \%$ & $17.4 \%$ & $21.3 \%$ & 5.1 \\
\hline
\end{tabular}

${ }^{*} \mathrm{CV}$ is coefficient of variation.

Followup of one-year-olds to age 5 from 1998-99 to 2002-3.

NLSCY data with longitudinal weights.

the sample design and also incorporate a poststratification element to correct for biases resulting from sample attrition. To do so, we used the SAS macro BOOTVAR 3.1 (Statistics Canada version of February 2005) as well as the survey data (svy) commands in STATA.

\section{Results}

Our sample comprises 3,923 five-year-old children, representing the population of 0-1-year-olds who were followed up to age $4-5$. Weighted estimates show that there are $49 \%$ girls and $51 \%$ boys at the population level, and $15 \%$ of the population is from visible minority groups. The most frequently occurring visible minority group was South Asian $(5.6 \%)$ with none of the remaining groups exceeding $2.5 \%$. One-third of the parents reported having an education level of high school completion or less, while $64 \%$ had high school education or above. The majority of children, $85 \%$ of the population, lived in two-parent as opposed to the rest $15 \%$ of the population in one-parent families. One-fifth of the children had at least one parent who was born outside Canada. $43 \%$ of the children lived in large cities of 500,000 residents or more, $14 \%$ lived in cities of from 100,000 to under 500,000, and 43\% lived in smaller cities, towns, or rural areas. Geographically speaking, $41 \%$ of the children lived in Ontario, 22\% in Quebec, 12\% in British Columbia, 11\% in Alberta, and the rest lived in all other six provinces in Canada.

In measuring children's longitudinal incidence of exposure to disadvantaged and unfavorable neighborhoods, we defined disadvantaged Census Tracts as those where 32\% or more of households had income below the LICO at the 2001 Census, which is consistent with previous work in Canada [43-45]. Using this definition, we found that $8 \%$ of children (Confidence Interval (CI) is $7 \%$ to $9 \%$ ) had been living in a low-income Census tract on at least one of the three observed occasions, while $4 \%$ had lived in such an economically disadvantaged neighborhood at all three of the data collection cycles, as shown in Table 1.

In case Census Tracts might be considered too large to be considered as neighborhoods we also compared children's incidence of exposure to low-income Dissemination Areas (DAs). This comparison shows that $8.6 \%$ of children were in DAs with $32 \%$ or more households below the LICO at Cycle 5 economically disadvantaged DAs (Confidence Interval is between $7.3 \%$ and $9.9 \%$ ) (Results are available upon request).

Our aggregated measures of perceived neighborliness (collective efficacy) and perceived safety show that $12 \%$ of children (CI: $11 \%$ to $14 \%$ ) had lived in an unneighborly neighborhood (with a low score of collective efficacy) on at least one of the three data collection occasions, while $4 \%$ had lived in such a disadvantaged neighborhood at all three of the data collection cycles, as shown in Table 1.

We then compared children's longitudinal exposure to household and neighborhood disadvantages. As Table 2 shows, children's exposure to low-income households does not necessarily mean their exposure to disadvantaged or unneighborly neighborhoods. Children in Quebec, the Maritimes, and Prairies provinces are more likely than their peers in Ontario to be exposed to low-income households. However, only children in Quebec suffer from exposure to a double disadvantaged environment-where disadvantages are shown in both low-income households and unneighborly neighborhoods. That is, in addition to an elevated risk of repeatedly being in low-income households, children in Quebec bear a significantly greater possibility of being exposed to both poor and unneighborly neighborhoods, compared to children in Ontario.

Children's ethnic origins seem to be more related to their exposure to low-income households than to disadvantaged neighborhoods. Compared to nonvisible minorities, aboriginal children are around 15 times more likely to be exposed to low-income households. Also, the odds of exposure to low-income households are 5 times higher for children described as Black and 1.9 times higher for South Asian children. While there are no corresponding effects of ethnic background on the odds of exposure to low-income neighborhoods, children described as Black were more likely to be exposed to unneighborly neighborhoods; their odds being almost 6 times higher than that of nonvisible minority children. 
TABLE 2: Predicting repeated exposures to household or neighbourhood disadvantage from age 1 to age 5.

\begin{tabular}{|c|c|c|c|c|c|c|c|c|c|c|c|c|}
\hline & \multicolumn{4}{|c|}{ Times in poor household } & \multicolumn{4}{|c|}{ Times in poor neighbourhood } & \multicolumn{4}{|c|}{$\begin{array}{c}\text { Times in un-neighbourly } \\
\text { neighbourhood }\end{array}$} \\
\hline & $b$ & $t$ & $P$ & $\begin{array}{l}\text { Odds } \\
\text { ratio* }\end{array}$ & $b$ & $t$ & $P$ & $\begin{array}{l}\text { Odds } \\
\text { ratio* }\end{array}$ & $b$ & $t$ & $P$ & $\begin{array}{l}\text { Odds } \\
\text { ratio* }\end{array}$ \\
\hline Intercept & 0.19 & 3.82 & 0.000 & 0.0 & 0.25 & 3.71 & 0.000 & 0.2 & 0.15 & 4.52 & 0.000 & \\
\hline \multicolumn{13}{|l|}{ Province (ref.: Ontario) } \\
\hline Maritimes & 0.29 & 4.58 & 0.000 & 3.0 & 0.14 & 3.17 & 0.002 & 3.7 & -0.03 & -0.81 & 0.420 & 0.39 \\
\hline Quebec & 0.23 & 3.74 & 0.000 & 2.4 & 0.18 & 3.78 & 0.000 & 2.5 & 0.13 & 2.90 & 0.004 & 1.6 \\
\hline Prairies & 0.18 & 3.40 & 0.001 & 1.4 & 0.00 & 0.03 & 0.974 & 0.6 & 0.07 & 1.76 & 0.078 & 1.18 \\
\hline $\mathrm{BC}$ & 0.00 & -0.05 & 0.960 & 0.7 & -0.02 & -0.51 & 0.608 & 0.6 & -0.01 & -0.26 & 0.793 & 0.7 \\
\hline Female & 0.02 & 0.49 & 0.625 & 1.2 & 0.03 & 0.97 & 0.331 & 0.9 & -0.02 & -0.66 & 0.508 & 1.1 \\
\hline \multicolumn{13}{|l|}{ Visible Minorities (ref.: other) } \\
\hline Black & 0.92 & 4.00 & 0.000 & 6.0 & 0.28 & 1.36 & 0.175 & 1.5 & 0.56 & 2.25 & 0.025 & 6.8 \\
\hline Chinese & 0.14 & 0.76 & 0.448 & 0.9 & 0.18 & 0.88 & 0.378 & 3.2 & 0.00 & 0.01 & 0.991 & 1.78 \\
\hline Native/aboriginal & 1.36 & 7.06 & 0.000 & 16.3 & 0.06 & 0.83 & 0.409 & 0.5 & 0.13 & 1.51 & 0.130 & 1 \\
\hline South Asian & 0.51 & 3.42 & 0.001 & 2.9 & 0.10 & 0.56 & 0.573 & 1.7 & 0.16 & 1.17 & 0.243 & 4.07 \\
\hline PMK spoke non-official language & 0.18 & 2.43 & 0.015 & 1.7 & 0.07 & 0.79 & 0.432 & 0.9 & 0.07 & 1.23 & 0.218 & 1.3 \\
\hline PMK born outside Canada & 0.10 & 1.33 & 0.182 & 1.1 & 0.22 & 2.99 & 0.003 & 4.0 & 0.02 & 0.37 & 0.712 & 0.81 \\
\hline \multicolumn{13}{|l|}{ Size of settlement (ref.: over $500 \mathrm{~K}$ ) } \\
\hline Rural area & 0.03 & 0.25 & 0.801 & 0.7 & 0.02 & 0.33 & 0.740 & 2.6 & -0.13 & -3.72 & 0.000 & 0.2 \\
\hline Urban under $30 \mathrm{~K}$ & 0.02 & 0.39 & 0.697 & 0.8 & -0.01 & -0.10 & 0.921 & 0.6 & -0.08 & -2.00 & 0.046 & 0.45 \\
\hline Urban from $30 \mathrm{~K}$ to $10 \mathrm{C}$ & 0.37 & 5.15 & 0.000 & 2.1 & -0.06 & -0.92 & 0.360 & 0.3 & 0.05 & 0.84 & 0.402 & 0.88 \\
\hline Urban from $100 \mathrm{~K}$ to $5 \mathrm{C}$ & 0.10 & 1.80 & 0.072 & 1.1 & -0.10 & -2.65 & 0.008 & 0.4 & 0.06 & 1.28 & 0.201 & 1.53 \\
\hline CSD used for Census profile & $\mathrm{n} / \mathrm{a}$ & & & & -0.14 & -2.69 & 0.007 & 0.2 & $\mathrm{n} / \mathrm{a}$ & & & $\mathrm{n} / \mathrm{a}$ \\
\hline
\end{tabular}

Followup of one-year-olds to age 5 from 1998-99 to 2002-3.

NLSCY data with longitudinal weights, OLS Regressions with bootstrap weights, and Odds ratios from binary logistic regression with bootstrap weights.

Having a home language other than English or French is significantly associated with the odds of children being exposed to low-income households but not with their odds of being exposed to low-income neighborhoods. If the child's parent spoke neither official language, the odds of the child respondent being exposed to poor households would be $70 \%$ higher than that of children whose parent spoke either of the official languages. On the other hand, parental immigration status shows a significant effect at the neighborhood level but not at the household level. If the parent informant was born outside Canada, her or his children have three times greater odds of repeated exposure to a poor neighborhood, as compared to those children whose parent informants were born in Canada.

In short, while residing in Quebec, being Black, and having a parent who was born outside Canada are related to children's exposure to disadvantaged or unneighborly neighborhoods, a child's exposure to low-income households itself is not necessarily related to his or her exposure to a disadvantaged neighborhood. Our Hypothesis 1 is supported. Namely, children's from disadvantaged households are not necessarily also exposed to disadvantaged neighborhoods.

We also examined the longitudinal incidence of young children moving between neighborhoods. Table 3 shows that while the income level of the origin neighborhood does not significantly influence the chance for a child to move out, the collective efficacy level of the origin neighborhood is indeed associated with children's residential mobility. With other characteristics held constant, every one-unit increase of the aggregated neighborhood score decreases the odds of children moving between neighborhoods by $20 \%$. Hypothesis 2 has therefore been substantiated.

We took a further look at residential changes between different observation occasions. Not surprisingly, children originally living in rented housing were more likely to move than those in owned housing (odds ratio is 2.4 for postcode change between first and second interviews, 2.4 for address change between first and third interviews, and 2.8 for the change between second and third interviews). Children born to mothers under 30 were more likely to move than those born to older mothers through the comparisons between three observation occasions. Younger children from large families are less likely to move. These results are consistent with the view that moving from one neighborhood to another is associated with household formation and likely with the transition to home ownership in the earlier stages of the family life cycle. Young children who have older siblings are likely to have parents who have settled down. By contrast, children born to mothers aged 29 or less are more likely still to be in the early stages of the family life cycle. 
Table 3: Predicting the odds that a child made a residential move between age 1 and age 5 years.

\begin{tabular}{|c|c|c|c|c|c|c|}
\hline & \multicolumn{2}{|c|}{$\begin{array}{l}\text { Moved between cycles } 3 \\
\text { and } 4\end{array}$} & \multicolumn{2}{|c|}{$\begin{array}{l}\text { Moved between cycles } 3 \\
\text { and } 5\end{array}$} & \multicolumn{2}{|c|}{$\begin{array}{l}\text { Moved between cycles } 4 \\
\text { and } 5\end{array}$} \\
\hline & $P$ & Odds ratio & $P$ & Odds ratio & $P$ & Odds ratio \\
\hline \multicolumn{7}{|l|}{ Origin neighbourhood properties } \\
\hline Aggregated neighbours score & 0.000 & 0.8 & 0.000 & 0.8 & 0.000 & 0.8 \\
\hline Child was in a poor neighbourhood & 0.684 & 0.9 & 0.717 & 1.1 & 0.275 & 0.7 \\
\hline 2001 census prop not moved in past $5 \mathrm{yrs}$ & 0.340 & 0.6 & 0.189 & 0.5 & 0.049 & 0.3 \\
\hline 2001 Census median income & 0.864 & 1.0 & 0.337 & 1.0 & 0.521 & 1.0 \\
\hline \multicolumn{7}{|l|}{ Origin household properties } \\
\hline Child age in months + B50 & 0.028 & 0.9 & 0.399 & 1.0 & 0.042 & 1.1 \\
\hline Dwelling is rented & 0.000 & 2.4 & 0.000 & 2.5 & 0.000 & 2.8 \\
\hline Number of bedrooms & 0.179 & 0.9 & 0.856 & 1.0 & 0.896 & 1.0 \\
\hline Biological mother $15-24$ at child birth & 0.016 & 1.6 & 0.034 & 1.5 & 0.190 & 1.3 \\
\hline Biological mother 25-29 at child birth & 0.015 & 1.4 & 0.000 & 1.8 & 0.001 & 1.7 \\
\hline One parent at cycle 3 & 0.157 & 1.4 & 0.364 & 1.3 & 0.883 & 1.0 \\
\hline Stepfamily at cycle 3 & 0.029 & 1.8 & 0.013 & 1.7 & 0.229 & 1.4 \\
\hline One child older at cycle 3 & 0.016 & 0.7 & 0.001 & 0.7 & 0.414 & 0.9 \\
\hline Several kids older at cycle 3 & 0.022 & 0.6 & 0.003 & 0.6 & 0.073 & 0.7 \\
\hline None younger at cycle 3 & 0.018 & 0.6 & 0.375 & 0.8 & 0.786 & 1.0 \\
\hline Count of occasions when child below LICO & 0.641 & 0.9 & 0.703 & 1.0 & 0.048 & 1.3 \\
\hline Recoded household income & 0.594 & 1.0 & 0.583 & 1.0 & 0.105 & 1.2 \\
\hline \multicolumn{7}{|l|}{ Size of settlement (ref.: over $500 \mathrm{~K}$ ) } \\
\hline Rural area & 0.997 & 1.0 & 0.882 & 1.1 & 0.615 & 1.2 \\
\hline Urban under $30 \mathrm{~K}$ & 0.920 & 1.0 & 0.690 & 1.2 & 0.882 & 1.1 \\
\hline Urban from $30 \mathrm{~K}$ to $100 \mathrm{~K}$ & 0.873 & 1.1 & 0.111 & 1.6 & 0.047 & 2.2 \\
\hline Urban from $100 \mathrm{~K}$ to $500 \mathrm{~K}$ & 0.486 & 1.1 & 0.032 & 1.4 & 0.011 & 1.7 \\
\hline \multicolumn{7}{|l|}{ Province (ref.: Ontario) } \\
\hline Maritimes & 0.140 & 1.4 & 0.173 & 1.3 & 0.213 & 1.3 \\
\hline Quebec & 0.103 & 1.4 & 0.077 & 1.4 & 0.583 & 1.1 \\
\hline Prairies & 0.107 & 1.4 & 0.064 & 1.4 & 0.014 & 1.6 \\
\hline $\mathrm{BC}$ & 0.896 & 1.0 & 0.808 & 0.9 & 0.724 & 0.9 \\
\hline CSD used for Census profile & 0.967 & 1.0 & 0.477 & 0.8 & 0.739 & 0.9 \\
\hline Length of risk period & 0.001 & 1.1 & 0.211 & 1.1 & 0.001 & 1.2 \\
\hline Intercept & 0.376 & 0.4 & 0.206 & 0.0 & 0.000 & 0.0 \\
\hline
\end{tabular}

Followup of one-year-olds to age 5 from 1998-99 to 2002-3.

NLSCY data with longitudinal weights, Odds ratios from binary logistic regresson with bootstrap weights.

Thus, "neighborhood effects" interact with birth order and life cycle effects and must be correctly estimated with those factors controlled.

5.1. Neighborhood Poverty and Social Capital Effects on Children's PreSchool Abilities. We used receptive vocabulary, measured through the Peabody test (PPVT-R), to indicate children's socially related abilities while "Who Am I?" and Number Knowledge tests to indicate children's other abilities. Other covariates being controlled, the aggregated collective efficacy score, and the measure of "ever in a poor neighborhood" only significantly influence children's receptive vocabulary scores. As Table 4 shows, while the aggregated collective efficacy score increases a child's receptive vocabulary score, "ever in a poor neighborhood" shows a strongly negative effect. Thus, Hypothesis 3 is supported.

After neighborhood-level income was controlled, the link between the collective efficacy scale and receptive vocabulary scores remained highly significant; however, associations between neighborhood collective efficacy and other cognitive outcomes became nonsignificant. This implies that associations between other vocabulary-irrelevant cognitive outcomes and neighborhood collective efficacy can be explained as being confounded with or arising from general economic advantage/disadvantage. In other words, children's vocabulary-irrelevant cognitive outcomes are directly influenced by the neighborhood's economic traits but not by the neighborhood's collective efficacy, or social capital. 
TABle 4: Predicting cognitive outcomes at age 5 using neighbourhood variables and child- and family-level variables.

\begin{tabular}{|c|c|c|c|c|c|c|c|c|c|c|c|}
\hline & \multicolumn{2}{|c|}{$\begin{array}{l}\text { Vocabulary } \\
\text { PPVT-R }\end{array}$} & \multicolumn{2}{|c|}{$\begin{array}{c}\text { Overall } \\
\text { who am I? }\end{array}$} & \multicolumn{2}{|c|}{$\begin{array}{l}\text { Copying } \\
\text { who am I? }\end{array}$} & \multicolumn{2}{|c|}{$\begin{array}{l}\text { Symbols } \\
\text { who am I? }\end{array}$} & \multicolumn{3}{|c|}{ Number knowledge } \\
\hline & Coef. & $P$ & Coef. & $P$ & Coef. & $P$ & Coef. & $P$ & Coef. & $\begin{array}{l}\text { Odds } \\
\text { ratio }\end{array}$ & $P$ \\
\hline Age in months at Cyc 5 interview & & $\mathrm{n} / \mathrm{a}$ & 0.533 & 0.000 & 0.231 & 0.000 & 0.303 & 0.000 & 0.096 & 1.100 & 0.000 \\
\hline Aggregated neighbours score & 0.876 & 0.001 & 0.116 & 0.189 & 0.047 & 0.301 & 0.070 & 0.210 & 0.044 & 1.045 & 0.339 \\
\hline Aggregated safety score & 0.652 & 0.166 & -0.147 & 0.273 & -0.137 & 0.043 & -0.010 & 0.910 & 0.102 & 1.108 & 0.145 \\
\hline Ever in a poor neighbourhood & -4.303 & 0.008 & 0.460 & 0.329 & 0.259 & 0.339 & 0.201 & 0.467 & 0.032 & 1.032 & 0.898 \\
\hline CSD for Census profile data & 0.803 & 0.545 & 0.110 & 0.759 & 0.001 & 0.996 & 0.109 & 0.653 & 0.013 & 1.014 & 0.951 \\
\hline 2001 census prop stayed past $5 \mathrm{yrs}$ & 5.985 & 0.070 & -0.061 & 0.949 & 0.233 & 0.628 & -0.294 & 0.621 & -0.167 & 0.846 & 0.736 \\
\hline 2001 Census median income & 0.051 & 0.325 & 0.029 & 0.058 & 0.021 & 0.011 & 0.008 & 0.383 & 0.003 & 1.003 & 0.758 \\
\hline \multicolumn{12}{|l|}{ Province (ref: Ontario) } \\
\hline Maritimes & -0.016 & 0.990 & -0.467 & 0.194 & -0.046 & 0.788 & -0.421 & 0.063 & -0.307 & 0.735 & 0.046 \\
\hline Quebec & -6.457 & 0.006 & -2.182 & 0.000 & -0.057 & 0.734 & -2.125 & 0.000 & -0.573 & 0.564 & 0.000 \\
\hline Prairies & 0.380 & 0.698 & -1.572 & 0.000 & -0.258 & 0.128 & -1.314 & 0.000 & -0.180 & 0.836 & 0.275 \\
\hline $\mathrm{BC}$ & 2.017 & 0.206 & -0.819 & 0.033 & 0.034 & 0.867 & -0.854 & 0.000 & -0.169 & 0.845 & 0.373 \\
\hline Female & 1.465 & 0.029 & 2.405 & 0.000 & 0.830 & 0.000 & 1.576 & 0.000 & 0.107 & 1.113 & 0.322 \\
\hline \multicolumn{12}{|l|}{ Visible Minorities (ref: Other) } \\
\hline Black & -6.999 & 0.003 & -0.187 & 0.860 & -0.331 & 0.531 & 0.144 & 0.817 & -0.781 & 0.458 & 0.085 \\
\hline Chinese & -1.447 & 0.691 & 2.847 & 0.009 & 1.354 & 0.001 & 1.493 & 0.061 & 0.606 & 1.833 & 0.250 \\
\hline Native/Aboriginal & -4.823 & 0.159 & -0.461 & 0.566 & -0.139 & 0.758 & -0.322 & 0.531 & -0.087 & 0.498 & 0.103 \\
\hline South Asian & -8.116 & 0.003 & 2.072 & 0.004 & 0.890 & 0.018 & 1.181 & 0.010 & -0.696 & 1.210 & 0.590 \\
\hline Francophone outside Quebec & -13.273 & 0.000 & -1.103 & 0.035 & -0.142 & 0.540 & -0.961 & 0.024 & -0.543 & 0.581 & 0.182 \\
\hline $\begin{array}{l}\text { PMK mother tongue not English } \\
\text { not French }\end{array}$ & -2.543 & 0.085 & 0.553 & 0.163 & 0.246 & 0.235 & 0.307 & 0.223 & -0.087 & 0.916 & 0.685 \\
\hline PMK born outside Canada & -2.971 & 0.024 & 0.303 & 0.425 & 0.088 & 0.653 & 0.215 & 0.374 & -0.171 & 0.843 & 0.368 \\
\hline PMK has post 2 ndary education & 3.168 & 0.000 & 0.560 & 0.021 & 0.261 & 0.030 & 0.298 & 0.048 & 0.300 & 1.350 & 0.010 \\
\hline $\begin{array}{l}\text { Biological mother } 15-24 \text { at child } \\
\text { birth }\end{array}$ & -3.561 & 0.002 & -0.861 & 0.017 & -0.367 & 0.053 & -0.493 & 0.023 & -0.620 & 0.538 & 0.000 \\
\hline $\begin{array}{l}\text { Biological mother } 25-29 \text { at child } \\
\text { birth }\end{array}$ & -1.964 & 0.015 & -0.489 & 0.054 & -0.207 & 0.120 & -0.281 & 0.068 & -0.173 & 0.841 & 0.137 \\
\hline one parent at cycle 5 & -1.801 & 0.169 & -0.039 & 0.930 & 0.274 & 0.231 & -0.313 & 0.237 & 0.001 & 1.001 & 0.996 \\
\hline stepfamily at cycle 5 & 1.056 & 0.337 & -0.447 & 0.219 & -0.112 & 0.589 & -0.335 & 0.121 & -0.257 & 0.773 & 0.143 \\
\hline one child older at cycle 5 & -2.816 & 0.000 & -0.321 & 0.237 & 0.045 & 0.751 & -0.366 & 0.029 & 0.058 & 1.060 & 0.661 \\
\hline Several kids older at cycle 5 & -6.301 & 0.000 & -0.974 & 0.002 & -0.127 & 0.429 & -0.847 & 0.000 & -0.309 & 0.734 & 0.084 \\
\hline none younger at cycle 5 & 0.794 & 0.294 & 0.232 & 0.361 & -0.036 & 0.778 & 0.268 & 0.095 & -0.014 & 0.986 & 0.912 \\
\hline $\begin{array}{l}\text { Count of occasions child below } \\
\text { lico }\end{array}$ & -1.481 & 0.015 & -0.396 & 0.044 & -0.206 & 0.038 & -0.190 & 0.116 & 0.036 & 1.036 & 0.710 \\
\hline Recoded household income & -0.034 & 0.947 & 0.235 & 0.175 & 0.140 & 0.086 & 0.095 & 0.400 & 0.021 & 1.022 & 0.815 \\
\hline \multicolumn{12}{|l|}{ Size of settlement (ref: over $500 \mathrm{~K}$ ) } \\
\hline Rural area & -2.864 & 0.108 & -0.503 & 0.267 & -0.008 & 0.974 & -0.495 & 0.095 & -0.085 & 0.918 & 0.744 \\
\hline Urban under $30 \mathrm{~K}$ & -3.539 & 0.037 & -0.886 & 0.055 & -0.210 & 0.406 & -0.676 & 0.022 & -0.293 & 0.746 & 0.207 \\
\hline Urban from $30 \mathrm{~K}$ to $100 \mathrm{~K}$ & -1.865 & 0.134 & -0.635 & 0.086 & 0.081 & 0.660 & -0.716 & 0.003 & -0.155 & 0.856 & 0.505 \\
\hline Urban form $100 \mathrm{~K}$ to $500 \mathrm{~K}$ & -0.611 & 0.587 & -0.535 & 0.117 & -0.121 & 0.500 & -0.414 & 0.036 & -0.032 & 0.968 & 0.838 \\
\hline
\end{tabular}


TABLE 4: Continued.

\begin{tabular}{|c|c|c|c|c|c|c|c|c|c|c|c|}
\hline & \multicolumn{2}{|c|}{$\begin{array}{l}\text { Vocabulary } \\
\text { PPVT-R }\end{array}$} & \multicolumn{2}{|c|}{$\begin{array}{l}\text { Overall } \\
\text { who am I? }\end{array}$} & \multicolumn{2}{|c|}{$\begin{array}{l}\text { Copying } \\
\text { who am I? }\end{array}$} & \multicolumn{2}{|c|}{$\begin{array}{l}\text { Symbols } \\
\text { who am I? }\end{array}$} & \multicolumn{3}{|c|}{ Number knowledge } \\
\hline & Coef. & $P$ & Coef. & $P$ & Coef. & $P$ & Coef. & $P$ & Coef. & $\begin{array}{l}\text { Odds } \\
\text { ratio }\end{array}$ & $P$ \\
\hline Language test French & 6.269 & 0.007 & & & & & & & & & \\
\hline Intercept & 90.991 & 0.000 & -8.887 & 0.002 & -2.187 & 0.188 & -6.700 & 0.000 & -6.283 & 0.002 & 0.000 \\
\hline
\end{tabular}

Followup of one-year olds to age 5 from 1998-99 to 2002-3.

NLSCY data with longitudinal weights, OLS Regressons with bootstrap weights, Odds ratios from binary logistic regresson with bootstrap weights.

We then took into account child- and family-level variables. Child-level predictors include gender, age of mother at the child's birth, the number of times the child had been in a low-income household, and visible minority group. Family-level predictors include family size and structure indicators, highest schooling level, immigration status, mother tongue of the parent informant (PMK), household income, and size of the urban area where household was situated. After we controlled the above predictors, the impact of the neighborhood's collective efficacy score remains significant on receptive vocabulary but not on cognitive outcomes derived from the "Who Am I?" and Number Knowledge assessments. The same is true for the indicator of wether or not the child has ever lived in a low-income neighborhood. The highest level of schooling of the parent informant, the number of times the child had been in a family with household income below the LICO, gender, visible minority status, and province of residence show significant effects. Children resident in Quebec performed worse than those from Ontario on cognitive outcomes, with other covariates controlled.

\section{Discussion}

Focusing on a recent longitudinal cohort of Canadian children followed up over the preschool years, we have established the proportions about children's exposure to household poverty, neighborhood poverty, and lack of neighborhood collective efficacy between 1998 and 2003. We also demonstrated the prevalence of children's moving from one neighborhood to another over this part of childhood. Children have lower odds of moving away from neighborhoods with higher levels of collective efficacy. We had expected to find that changing residence would be associated with cognitive outcomes at age 5, but this turned out not to be the case.

Given the existing literature, we had expected to find associations between neighborhood collective efficacy and all child cognitive outcomes. In fact, we found that only receptive vocabulary as measured by the Peabody PPVT-R/EVIP had a robust association with neighborhood variables. Children from neighborhoods with higher levels of collective efficacy had higher receptive vocabulary scores, even after we controlled over child- and family-level variables. This is consistent with previous research [52]. However, we have not found any significant association between a neighborhood's collective efficacy score and non-language based cognitive outcomes, such as the copying and symbol use scales from the "Who Am I?" test and the Number Knowledge test. In similar fashion, the aggregated neighborhood safety score had a significant relationship only with the Copying subscale of the "Who Am I?" test. This suggests that the cognitive effects of neighborhood collective efficacy and neighborhood safety are narrowly confined to receptive vocabulary in English or French and do not generalize to other cognitive outcomes. This is reminiscent of the intelligence testing literature, in which it has been accepted that working class and minority children performed worse than middle class children on verbal tests but at the same level on "culture free" tests of logical and mathematical reasoning. Following this line of argument, neighborhood social cohesion and social capital, as evidenced by their effects on children's receptive vocabulary, appear to be aspects of the mainstream middleclass culture and may not be easily grafted on to impoverished neighborhoods. Understandably, poor neighborhoods tend to have low levels of collective efficacy. This gives rise to a significantly negative association between having ever been in a poor neighborhood and children's receptive vocabulary abilities.

On the other hand, the economic disadvantage at the neighborhood level seems to be more related to the "Who Am I?" test, in particular, the Copying subscale of this test. Compared to children in Ontario, children in Quebec do worse on several of the directly measured cognitive outcomes, with other covariates controlled.

Overall, in this study we found significant impacts of neighborhoods on children's school readiness, independent of socioeconomic characteristics at the household level. Particularly, social capital embedded in a neighborhood exerts a positive impact on children's receptive vocabulary abilities, despite economic disadvantages of the neighborhood. This study draws scholarly and policy attention to the importance of improving neighborhood environment for children's development, not only in the economic sense, but more importantly, also in the sense of social capital.

\section{Conflict of Interests}

The authors declare that there is no conflict of interests regarding the publication of this paper. 


\section{References}

[1] D. M. Blau, "The effect of income on child development," Review of Economics and Statistics, vol. 81, no. 2, pp. 261-276, 1999.

[2] H. A. Foster, Neighborhood and Family Contexts of Gendered Aggression in Childhood, vol. 62-04A, Dissertation Abstracts International, 2001.

[3] P. Cheshire, "Are mixed community policies evidence based? A review of the research on neighbourhood effects," in Neighbourhood Effects Research: New Perspectives Neighbourhood Effects Research: New Perspectives, M. van Ham, D. Manley, N. Bailey, L. Simpson, and D. Maclennan, Eds., pp. 295-297, Springer, New York, NY, USA, 2012.

[4] R. D. Putnam, Bowling Alone: the Collapse and Revival of American Community, Simon \& Schuster, New York, NY, USA, 2000.

[5] A. J. Bailey, J. D. Sargent, D. C. Goodman, J. Freeman, and M. J. Brown, "Poisoned landscapes: the epidemiology of environmental lead exposure in Massachusetts children 1990-1991," Social Science and Medicine, vol. 39, no. 6, pp. 757-766, 1994.

[6] J. S. Coleman, "Social capital in the creation of human capital," American Journal of Sociology, vol. 94, pp. S94-S120, 1988.

[7] A. Portes, "Social capital: its origins and applications in modern sociology," Annual Review of Sociology, vol. 24, pp. 1-24, 1998.

[8] R. J. Sampson, J. D. Morenoff, and F. Earls, "Beyond social capital: spatial dynamics of collective efficacy for children," American Sociological Review, vol. 64, no. 5, pp. 633-660, 1999.

[9] M. H. Boyle, K. Georgiades, Y. Racine, and C. Mustard, "Neighborhood and family influences on educational attainment: results from the Ontario Child Health Study Follow-Up 2001," Child Development, vol. 78, no. 1, pp. 168-189, 2007.

[10] W. J. Wilson, "Studying inner city dislocations: the challenge of public agenda research," American Sociological Review, vol. 56, pp. 1-14, 1991.

[11] R. Putnam, Making Democracy Work: Civic Traditions in Modern Italy, Princeton University Press, Princeton, NJ, USA, 1993.

[12] R. D. Putnam, "E pluribus unum: diversity and community in the twenty-first century the 2006 johan skytte prize lecture," Scandinavian Political Studies, vol. 30, no. 2, pp. 137-174, 2007.

[13] D. Ginther, R. Havemann, and B. Wolfe, "Neighbourhood attributes as determinants of children's outcomes: how robust are the relationships?" Journal of Human Resources, vol. 35, no. 4, pp. 603-642, 2000.

[14] W. A. V. Clark, "Reexamining the moving to opportunity study and its contribution to changing the distribution of poverty and ethnic concentration," Demography, vol. 45, no. 3, pp. 515-535, 2008.

[15] T. Leventhal and J. Brooks-Gunn, "Moving to oppurtunity: an experimental study of neighborhood effects on mental health," American Journal of Public Health, vol. 93, no. 9, pp. 1576-1582, 2003.

[16] T. Leventhal, R. C. Fauth, and J. Brooks-Gunn, "Neighborhood poverty and public policy: a 5-year follow-up of children's educational outcomes in the New York City moving to opportunity demonstration," Developmental Psychology, vol. 41, no. 6, pp. 933-952, 2005.

[17] P. Oreopoulos, "Neighbourhood effects in Canada: a critique," Canadian Public Policy, vol. 34, no. 2, pp. 237-258, 2008.

[18] R. J. Sampson, J. D. Morenoff, and T. Gannon-Rowley, "Assessing "neighborhood effects": social processes and new directions in research," Annual Review of Sociology, vol. 28, pp. 443-478, 2002.
[19] M. van Ham, D. Manley, N. Bailey, L. Simpson, and D. Maclennan, Eds., Neighbourhood Effects Research: New Perspectives, Springer, New York, NY, USA, 2012.

[20] M. van Ham, D. Manley, N. Bailey, L. Simpson, and D. Maclennan, Eds., Understanding Neighbourhood Dynamics: New Insights for Neighbourhood Effects Research, Springer, New York, NY, USA, 2013.

[21] W. Clark and N. Rivers, "Community choice in large cities: selectivity and ethnic sorting across neighborhoods," in Understanding Neighbourhood Dynamics: New Insights for Neighbourhood Effects Research, M. van Ham, D. Manley, N. Bailey, L. Simpson, and D. Maclennan, Eds., Springer, New York, NY, USA, 2013.

[22] D. Massey and M. L. Eggers, "The ecology of inequality: minorities and the concentration of poverty, 1970-1980," American Journal of Sociology, vol. 95, no. 5, pp. 1153-1188, 1990.

[23] P. Jargowsky, The Urban Underclass, The Brookings Institution, Washington, DC, USA, 1991.

[24] C. Jencks and S. E. Mayer, The Social Consequences of Growing Up in a Poor Neighborhood, National Academy Press, Washington, DC, USA, 1990, Inner City Poverty in the United States.

[25] R. J. Sampson, "Moving to inequality: neighborhood effects and experiments meet social structure," American Journal of Sociology, vol. 114, no. 1, pp. 189-231, 2008.

[26] W.-H. Chen and M. Corak, "Child poverty and changes in child poverty," Demography, vol. 45, no. 3, pp. 537-553, 2008.

[27] Z. L. Hajnal, "The nature of concentrated urban poverty in Canada and the United States," Canadian Journal of Sociology, vol. 20, no. 4, pp. 497-528, 1995.

[28] D. E. Kohen, J. Brooks-Gunn, T. Leventhal, and C. Hertzman, "Neighborhood income and physical and social disorder in Canada: associations with young children's competencies," Child development, vol. 73, no. 6, pp. 1844-1860, 2002.

[29] B. E. Harcourt and J. Ludwig, "Broken windows: new evidence from New York city and a five-city social experiment," University of Chicago Law Review, vol. 73, no. 1, pp. 271-320, 2006.

[30] J. Myles, G. Picot, and W. Pyper, Neighborhood inequality in Canadian cities. Business and labor markets division, Statistics, Ontario, Canada, 2000.

[31] A. Peters, "Is your community child-friendly?" Canadian Social Trends, no. 67, pp. 2-5, 2002.

[32] R. A. Walks and L. S. Bourne, "Ghettos in Canada's cities? Racial segregation, ethnic enclaves and poverty concentration in Canadian urban areas," Canadian Geographer, vol. 50, no. 3, pp. 273-297, 2006.

[33] R. A. Walks, "Economic restructuring and trajectories of sociospatial polarization in the twenty-first century Canadian city," in Canadian Urban Regions: Trajectories of Growth and Change, L. Bourne, T. Hutton, R. Shearmur, and J. Simmons, Eds., pp. 125-159, Oxford University Press, 2011.

[34] M. I. Jackson and R. D. Mare, "Cross-sectional and longitudinal measurements of neighborhood experience and their effects on children," Social Science Research, vol. 36, no. 2, pp. 590-610, 2007.

[35] F. D. Wilson, "Ethnic concentrations and labor-market opportunities," in Immigration and Opportunity: Race, Ethnicity, and Employment in the United States, F. D. Bean and S. Bell-Rose, Eds., pp. 106-140, Russell Sage Foundation, New York, NY, USA, 1999.

[36] T. R. Balakrishnan and J. Kralt, Segregation of Visible Minorities in Montreal, Toronto and Vancouver. Ethnic Canada, Copp Clark Pitman, Toronto, Canada, 1987. 
[37] A. Portes and L. Jensen, "What's an ethnic enclave? The case for conceptual clarity," Sociological American Review, vol. 52, no. 6, pp. 768-771, 1987.

[38] A. Portes and L. Jensen, "The enclave and the entrants: patterns of ethnic enterprise in Miami before and after Mariel," American Sociological Review, vol. 54, no. 6, pp. 929-949, 1989.

[39] J. M. Sanders and V. Nee, "Limits of ethnic solidarity in the enclave economy," American Sociological Review, vol. 52, no. 6, pp. 745-773, 1987.

[40] R. J. Sampson, J. D. Morenoff, and T. Gannon-Rowley, “Assessing "neighborhood effects": social processes and new directions in research," Annual Review of Sociology, vol. 28, pp. 443-478, 2002.

[41] R. J. Sampson and S. W. Raudenbush, "Systematic social observation of public spaces: a new look at disorder in urban neighborhoods," American Journal of Sociology, vol. 105, no. 3, pp. 603-651, 1999.

[42] R. J. Sampson and P. Sharkey, "Neighborhood selection and the social reproduction of concentrated racial inequality," Demography, vol. 45, no. 1, pp. 1-29, 2008.

[43] M. Hatfield, "Concentrations of poverty and distressed neighborhoods in Canada," Tech. Rep. W-97-1E, Government of Canada, Human Resources Development, Ottawa, Canada, 1997.

[44] T. Carter and C. Polevychok, Poverty Changes in Winnipeg Neighborhoods 1981-2001, University of Winnipeg, 2005, Research Highlight No. 5.

[45] J. Richards, Creating Choices: Rethinking Aboriginal Policy, Howe Institute, Toronto, Canada, 2006.

[46] J. D. Sargent, A. Bailey, P. Simon, M. Blake, and M. A. Dalton, "Census tract analysis of lead exposure in Rhode Island children," Environmental Research, vol. 74, no. 2, pp. 159-168, 1997.

[47] J. Surowiecki, The Wisdom of Crowds: Why the Many are Smarter Than the Few and How Collective Wisdom Shapes Business, Economies, Societies and Nations, Little, Brown, Boston, Mass, USA, 2004.

[48] E. Thomas, M.Readiness to Learn at School among Five-Year-Old Children in Canada, Children and Youth Research, Statistics Canada, Ottawa, Canada, 2006.

[49] J. B. McGuire, "The reliability and validity of a questionnaire describing neighborhood characteristics relevant to families and young children living in urban areas," Journal of Community Psychology, vol. 25, no. 6, pp. 551-566, 1997.

[50] S. Gibbons, "Neighborhood effects on educational achievement: evidence from the census and national child development survey," Centre for the Economics of Education, London School of Economics and Political Science, 2002.

[51] M. De Lemos, PatternS of Young Children's Development: An International Comparison of Development as Assessed by "Who Am I"? Human Resources Development Canada, Applied Research Branch, Ottawa, Canada, 2002.

[52] D. E. Kohen, J. Brooks-Gunn, T. Leventhal, and C. Hertzman, "Neighborhood income and physical and social disorder in Canada: associations with young children's competencies," Child development, vol. 73, no. 6, pp. 1844-1860, 2002. 

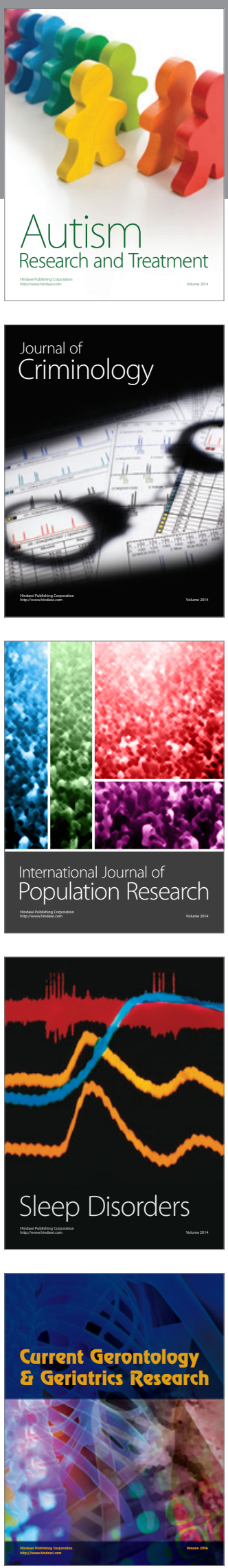
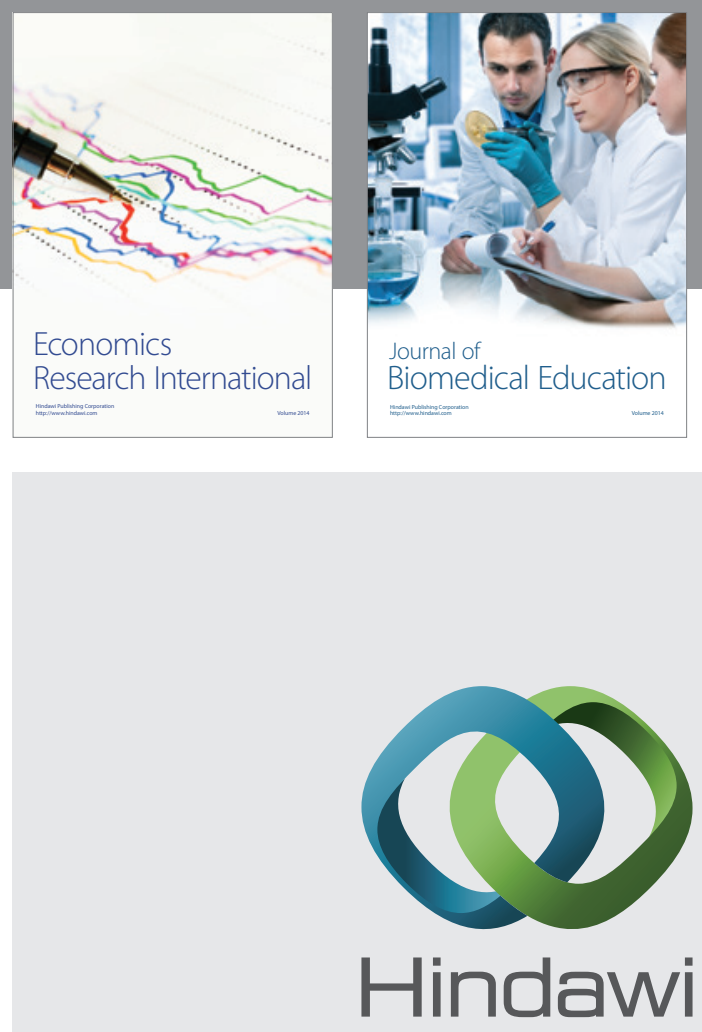

Submit your manuscripts at

http://www.hindawi.com
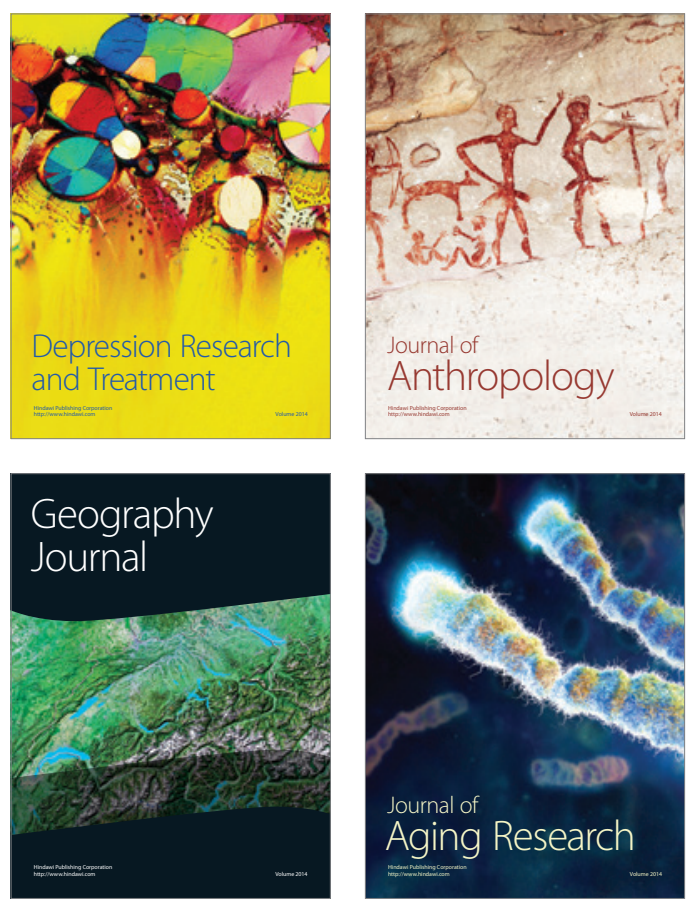
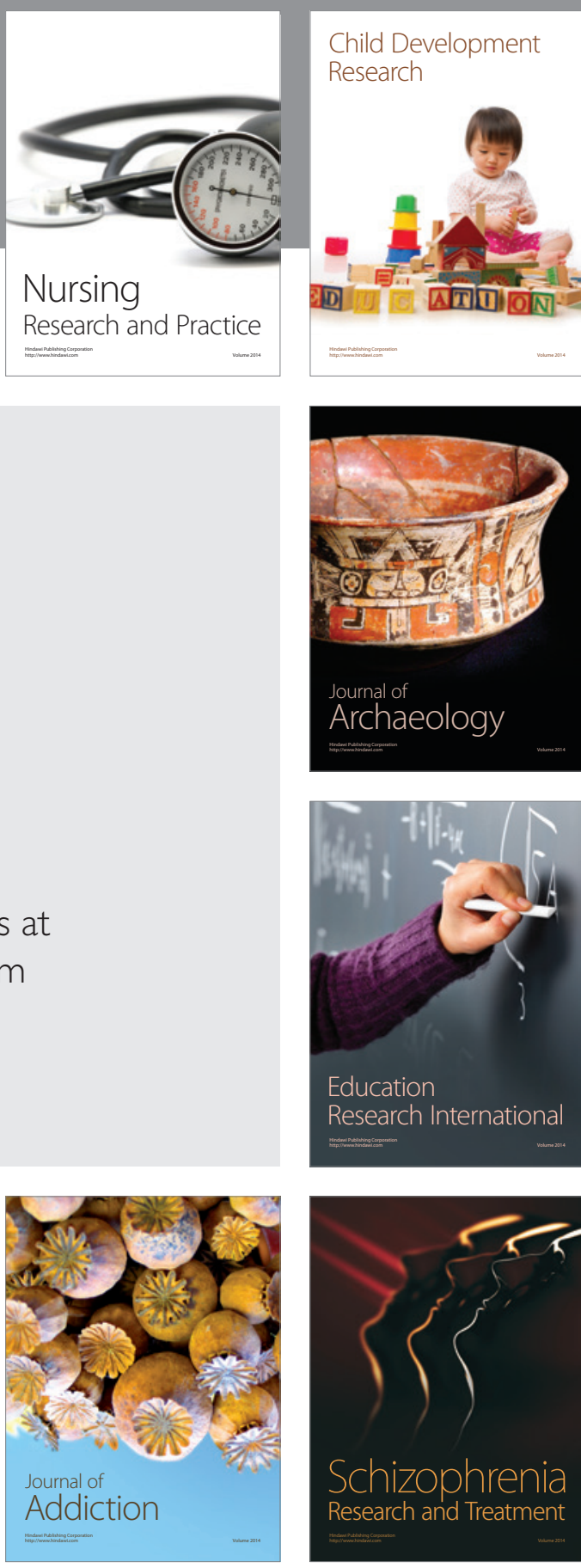

(D)
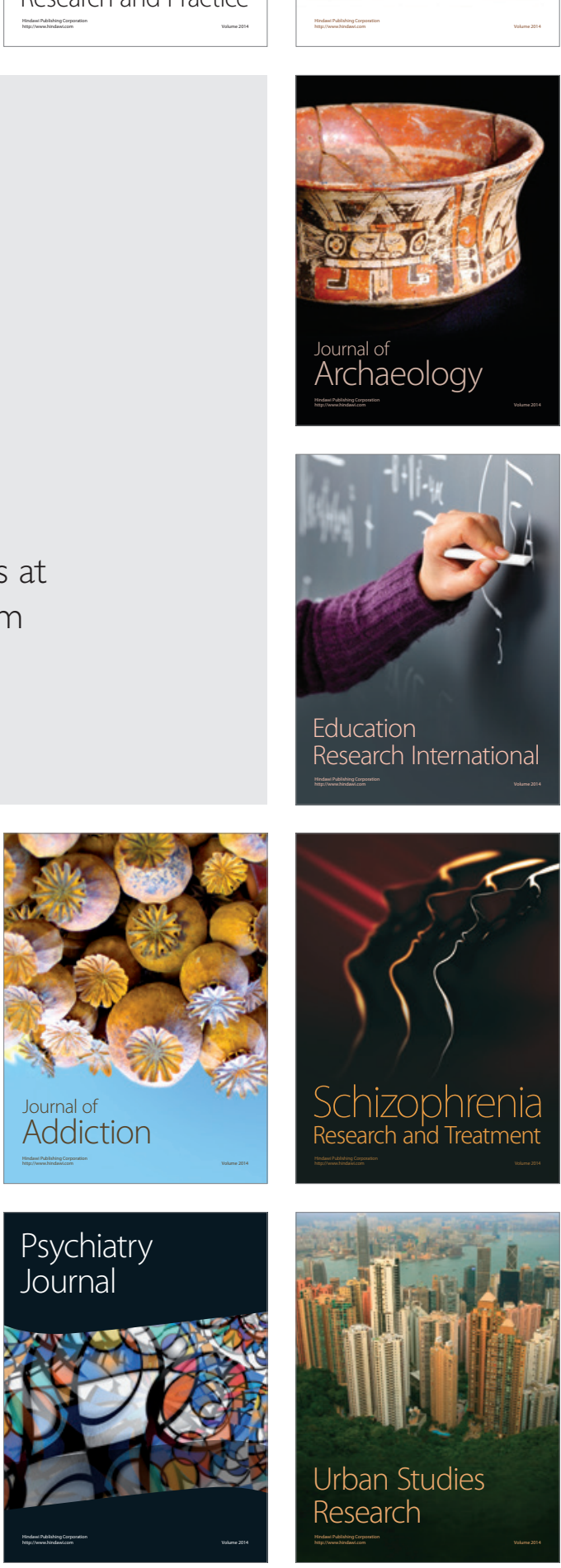